\title{
SYNTHESIS AND SPECTRAL CHARACTERIZATION ON PVA/PVP: GO BASED BLEND POLYMER ELECTROLYTES
}

\author{
SK. Shahenoor Basha ${ }^{1}$, M. Gnanakiran ${ }^{1}$, B. Ranjit Kumar ${ }^{1}$, K. Veera Bhadra \\ Reddy $^{2}$, M.V. Basaveswara Rao and M.C. Rao ${ }^{4}$,* \\ ${ }^{1}$ Solid State Ionics Laboratory, Department of Physics, K. L. University, Guntur-522502, India \\ ${ }^{2}$ Department of Physics, NRI Institute of Technology, Vijayawada Rural-520010, \\ Krishna District, India \\ ${ }^{3}$ Department of Chemistry, Krishna University, Machilipatnam-521001, India \\ ${ }^{4}$ Department of Physics, Andhra Loyola College, Vijayawada- 520008, India \\ *E-mail:raomc72@gmail.com
}

\begin{abstract}
Graphene oxide (GO) nanoparticles were dispersed in PVA/PVP blend polymers for preparation of nanocomposite polymer films by solution cast technique. SEM analysis revealed that graphene oxide is completely dispersed in blend polymer of PVA/PVP, resulting in the smooth surface background corresponds to amorphous nature of the host polymer. Raman spectra of PVA/PVP: GO; $(0.30 / 0.3)$ is recorded in the wavenumber range $600-3250 \mathrm{~cm}^{-1}$ at room temperature. DSC is used to measure the glass transition temperature $\left(\mathrm{T}_{\mathrm{g}}\right)$ as a function of wt $\%$ ratios of PVA/PVP:GO polymer electrolyte film and revealed that the glass transition temperature decreased monotonically, due to a lubricating effect with the increase of $\mathrm{GO}$ wt $\%$ (up to $0.3 \mathrm{wt} \%$ ) to the blend polymers. AC conductivity studies were performed onto the prepared nanocomposite polymer films. The conductivity is found to be $4.13 \times 10^{-4}$ $\mathrm{Scm}^{-1}$ for the films prepared at room temperature.
\end{abstract}

Keywords: PVA/PVP, Graphene oxide, Solution cast technique, SEM, Raman, DSC, AC conductivity.

(C) RASĀYAN. All rights reserved

\section{INTRODUCTION}

In the present scenario graphene and graphene oxide (GO), based materials have been applied in various fields due to their excellent potential, thermal and mechanical properties, ${ }^{1-4}$ such as conductive coating, sensors, microwave absorbing, energy storage devices etc. After the discovery of graphene and graphene oxide, a focus has been made on the non-volatile memory applications due to their potential applications. ${ }^{5}$ Nanocomposite polymer films are prepared by compounding the polymer and conductive nanoparticles such as graphite, carbon nanotubes, carbon fiber, carbon black and metal particles. ${ }^{3,4}$ When the content of conductive nanoparticles reaches to a critical value then a continuous electrically conductive network is formed rendering the polymer composite electrically conductive. ${ }^{6-8}$

Composite polymer electrolyte membranes with high ionic conductivity are widely used in many practical and industrial applications. Blend polymers with the complexation of graphene oxide can give electrolytes, which are mainly used in many applications such assolid-state batteries ${ }^{9}$, fuel cells ${ }^{10}$, energy storage devices ${ }^{11}$, smart windows ${ }^{12}$ and electrochromic devices ${ }^{13}$ etc. In order to improve the ionic conductivity of polymer electrolytes, plasticizers are added to the electrolytes in the presence of nanofillers. For instance, the blending of two polymers is a new avenue to improve ion conductivity. The complexation of polymer blends is physically similar but structurally different and has interlinking with hydrogen bonding, ionic and dipole interactions. Moreover, the physical and mechanical properties of the film depend upon the miscibility of the polymer blend such as charge transfer complexes for homopolymer mixtures. ${ }^{14}$ Graphene, a monolayer of hexagonally packed carbon atoms has revolutionized both the academic and industrial world ever since it comes to experimental existence. ${ }^{15,16}$ Graphene has excellent physical and mechanical properties such as high thermal conductivity and high mobility of charge carriers. ${ }^{17}$ Graphene is also used in many applications such as batteries, solar cells, fuel cells and 
super capacitors. ${ }^{18-21}$ Polyvinyl pyrrolidone (PVP) and polyvinyl alcohol (PVA) have chosen because they have excellent characteristics such as optical, mechanical and electrical as well as displaying dissolubility, stability, and large-scale screen printing of electrolyte films even at low cost. Rao et al. published their results on different materials in the earlier studies. ${ }^{22-56}$ In the present investigation, nanocomposite polymer films were prepared using dispersed GO nanoparticles with PVA/PVP blend polymers and successfully characterized by different spectroscopic techniques. The results obtained from these studies are prominent and suitable for energy storage devices and battery applications.

\section{Chemicals Required}

\section{EXPERIMENTAL}

Graphene oxide (acid treated 99\% purity) was purchased from Loba chemicals Ltd., India, polyvinyl pyrrolidone and polyvinyl pyrrolidone with average molecular weight of 36,000 were purchased from Sigma Aldrich chemicals Ltd., India.

\section{Preparation of Nanocomposite Polymer Films}

Nanocomposite polymer films are prepared with the combination of GO, PVA, and PVP. Take $200 \mathrm{ml}$ round bottom flask and add $30 \mathrm{ml}$ of distilled water with blend polymers of PVA/PVP: wt $\%(0.20 / 0.20$, $0.25 / 0.25$ and $0.30 / 0.30$ ) (equal wt $\%$ ratios of PVA/PVP). Stir all the mixtures till the polymers get dissolved in water, later reduced nanoparticles of GO: $\mathrm{x} \%(0.1,0.2$ and $0.3 \mathrm{~g})$ were added to the homogenous mixture and sonicate the solution to get fine dispersion, which was poured in polypropylene dishes and placed in hot air oven at $70{ }^{\circ} \mathrm{C}$. A fine nanocomposite polymer thin film was obtained which is kept in a desiccator until further test.

\section{SEM Analysis}

\section{RESULTS AND DISCUSSION}

The SEM image of host PVA/PVP: GO; (0.30/0.3) is shown in Fig.-1. It is observed that graphene oxide is completely dispersed in blend polymer of PVA/PVP, resulting in the smooth surface back ground corresponds to the amorphous nature of the host polymer, with an average thickness of $95 \mathrm{~nm}$. Figure-1 showed that the GO is well distributed with little aggregation in the polymer film.

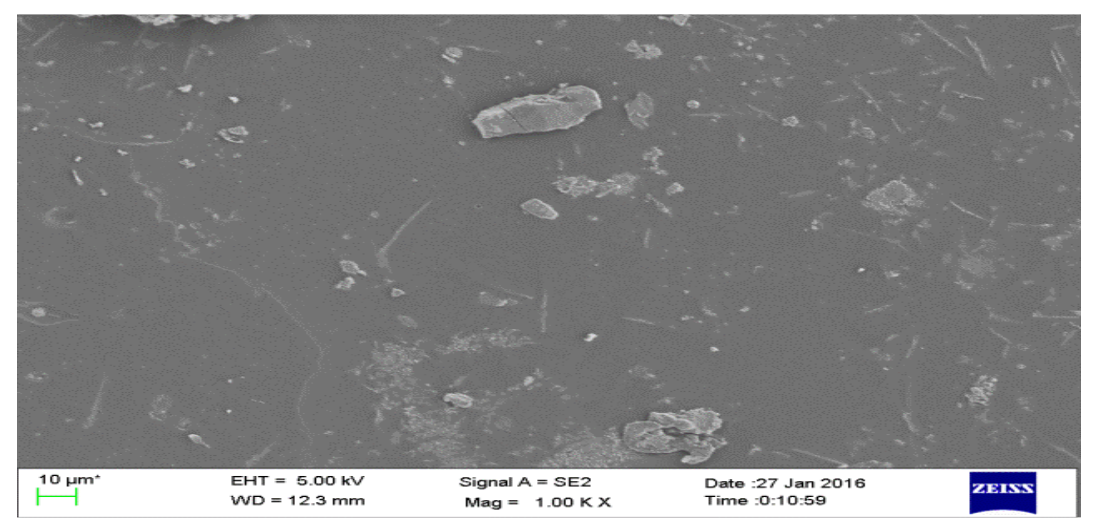

Fig.-1: SEM image of PVA/PVP:GO polymer electrolyte film for (0.30:0.3)wt\% ratio

Depending on the morphological surface of the film and its porosity nature, the enhancement of ionic conductivity is evidenced. ${ }^{57}$

\section{Raman Effect}

Raman spectroscopy is a very sensitive tool to measure the symmetric and asymmetric bands on an energy level and identifies the minor changes in the structure of the sample with carbon content. Figure- 2 
represents the Raman spectrum of PVA/PVP: GO (0.30/0.3) recorded in the wavenumber range 600-3250 $\mathrm{cm}^{-1}$ at room temperature. From the figure it has been observed that the Raman spectrum consists of two sharp peaks at 1232 and $1625 \mathrm{~cm}^{-1}$ corresponds to $\mathrm{C}-\mathrm{C}$ stretching and $\mathrm{C}-\mathrm{N}$ stretching bands for complexed polymer films respectively. Two wide bands with small intensity have been observed at 2200 and $2700 \mathrm{~cm}^{-1}$. These bands correspond to $\mathrm{C}-\mathrm{O}$ rocking, $\mathrm{O}-\mathrm{H}$ bending and $\mathrm{C}-\mathrm{H}$ bending; the position of the band indicates an interaction between proton with the carbonyl group and hydroxyl group. ${ }^{58}$ The broadening of peaks is evident that GO is completely dispersed in the polymer chains resulting in amorphous nature of the polymer electrolyte which satisfies with the SEM analysis.

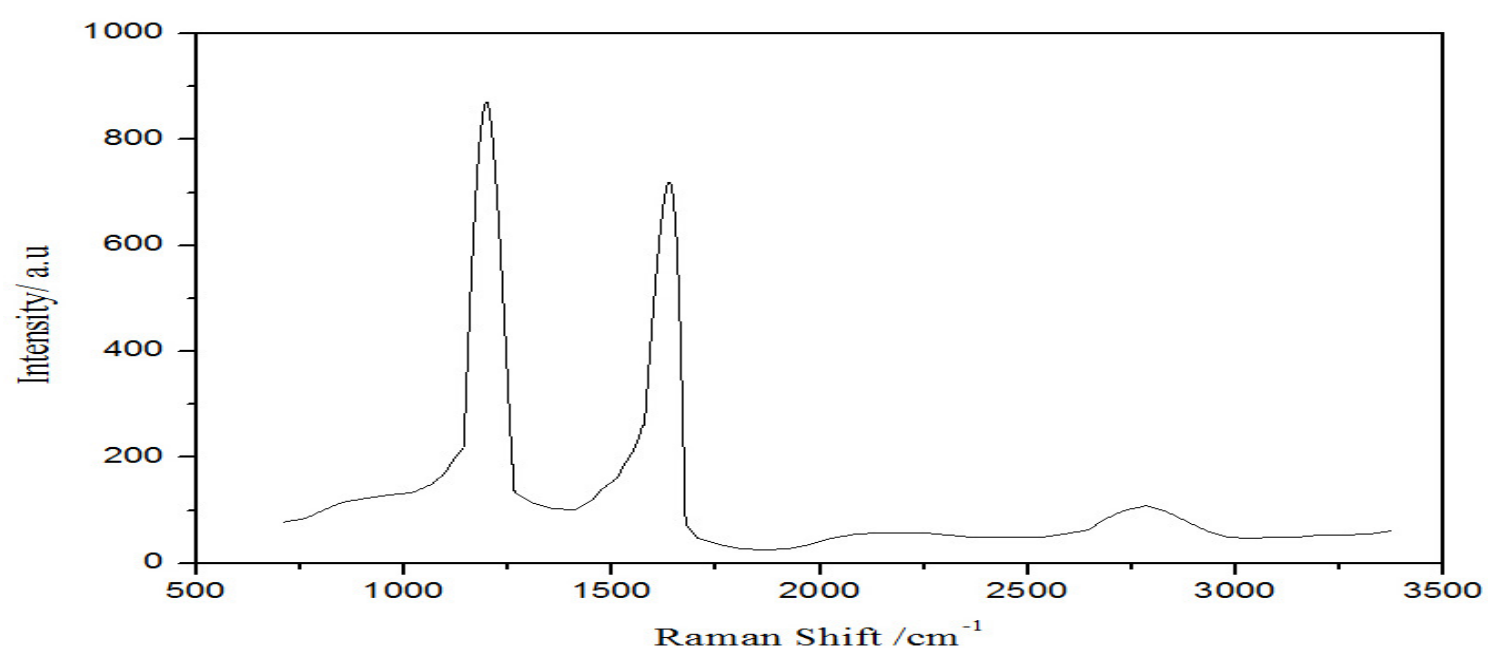

\section{DSC analysis}

Fig.-2: Raman spectrum of PVA/PVP:GO polymer electrolyte film for $(0.30: 0.3) \mathrm{wt} \%$ ratio

Figure-3 shows the variation of glass transition temperature $\left(\mathrm{T}_{\mathrm{g}}\right)$ as a function of wt\% ratios of PVA/PVP: GO polymer electrolyte films. As increasing the GO wt\% (up to $0.3 \mathrm{wt} \%$ ) to the blend polymers, the glass transition temperature is decreased monotonically, due to lubricating effect. A very low glass transition temperature at $30{ }^{\circ} \mathrm{C}$ and heat capacity were found for $0.3 \mathrm{wt} \%$ ratio of complexed 0.30PVA/0.30PVP blend polymers. Due to decrement in $\mathrm{T}_{\mathrm{g}}$, polymer gets soften and the wide gaps are formed through the material, where the moment of ions get freely pass through $\mathrm{it}^{59}$. Beyond this transition a long-range molecular motion occurs and thus the degree of rotational freedom increases, exhibiting a crystalline phase which restricts chain mobility in the amorphous phase. The functionalized groups between GO and PVA/PVP polymeric matrix demonstrated an adequate dispersion and exfoliation of carbon groups and consequently improving the thermal stability.

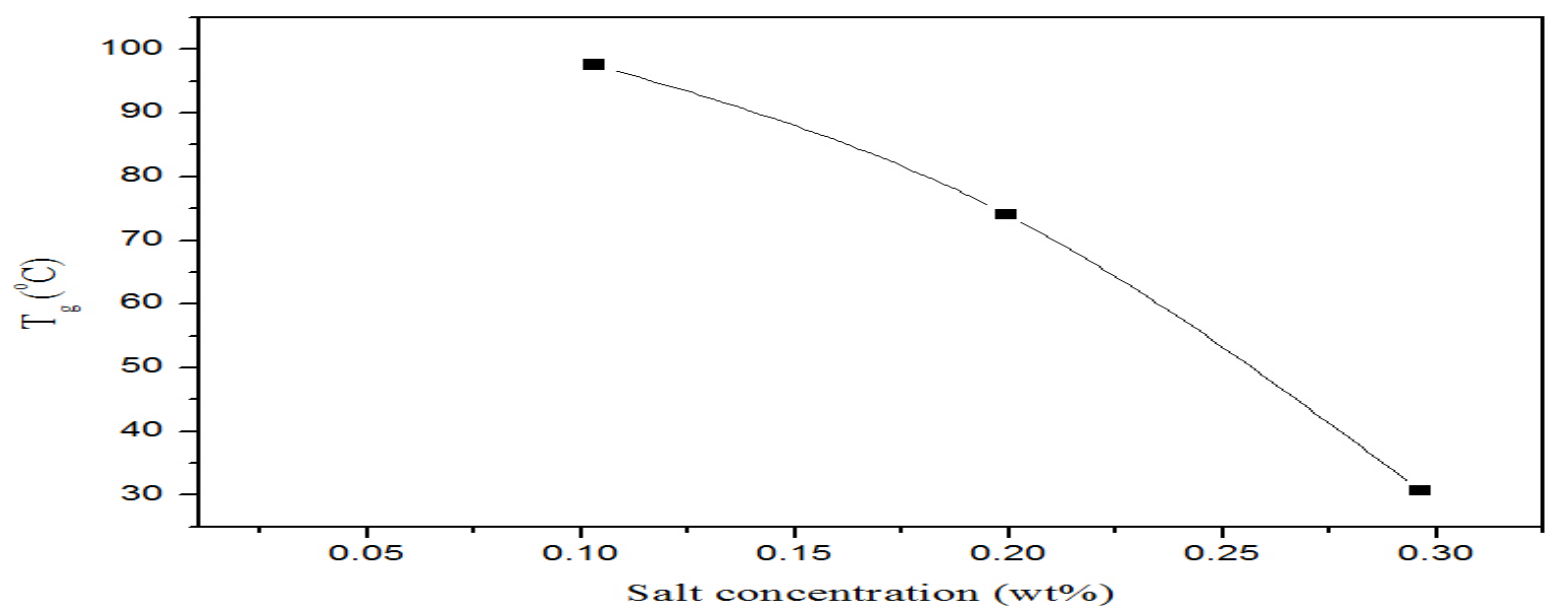

Fig.-3: Variation of glass transition temperature of PVA/PVP: GO polymer electrolyte film for (0.30:0.3)wt\% ratio 


\section{A.C. Conductivity Studies}

Impedance plots for the prepared nanocomposite polymer electrolytes for different wt $\%$ ratios have been shown in Fig.-4. In general complex impedance plot gives the information about the electrical properties of materials which shows two well-defined regions; at high-frequency region a semicircle is observed due to the parallel combination of a resistor and a capacitor and spike is obtained at a low frequency due to the formation of migration of ions at the electrode-electrolyte interfaces.

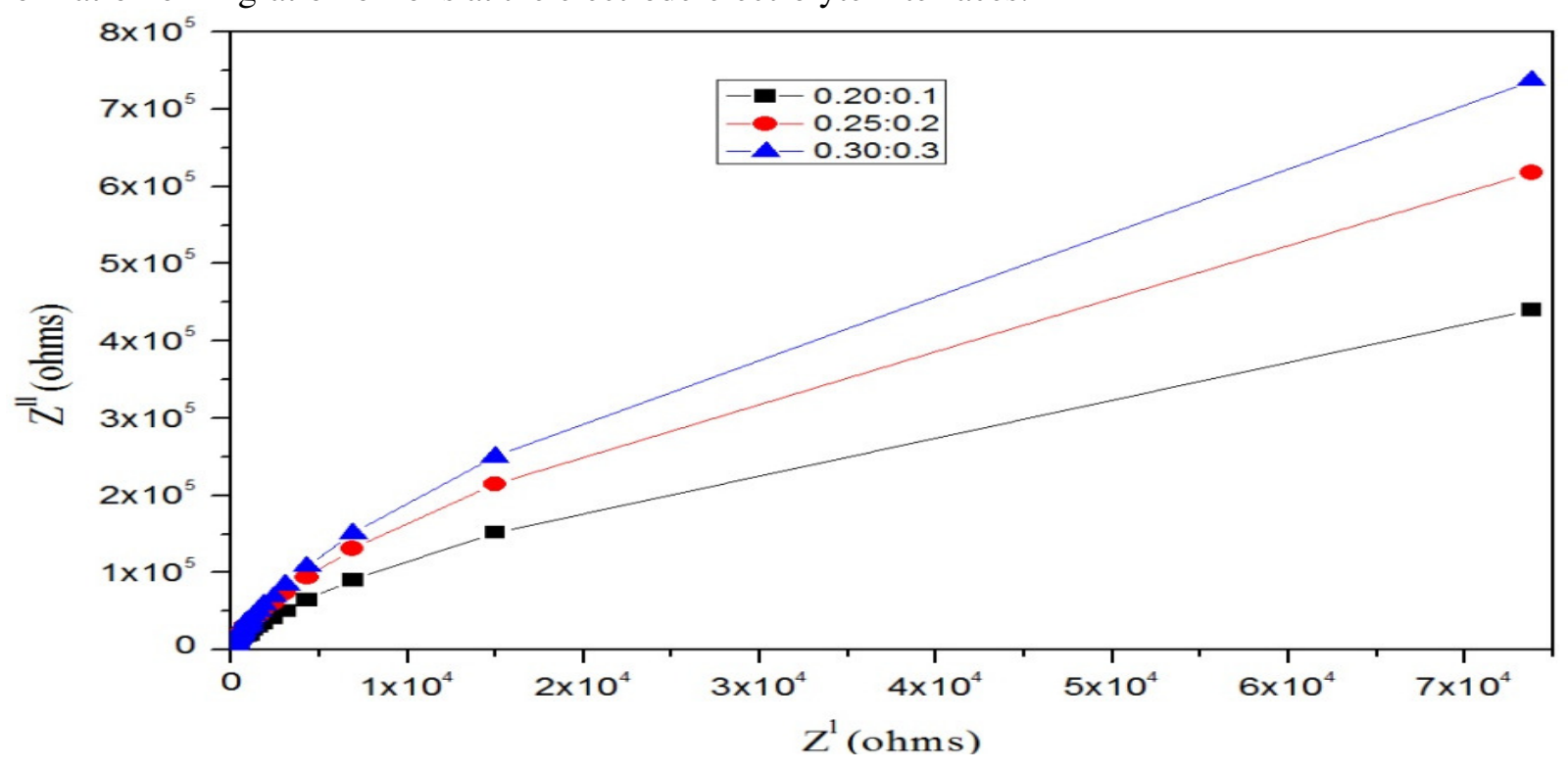

Fig.-4: Cole-Cole plots of polymer electrolyte films for different PVP/PVA: GO wt $\%$ ratios of (a) $(0.20: 0.1)(b)(0.25: 0.2)$ (c) $(0.30: 0.3)$

The impedance plot can be determined by varying real part $\left(\mathrm{Z}^{\mathrm{I}}\right)$ with respect to the imaginary part $\left(\mathrm{Z}^{\mathrm{II}}\right)$ and the ionic conductivity is calculated by the following relation:

$$
\sigma_{\mathrm{ac}}=\mathrm{t} /\left(\mathrm{R}_{\mathrm{b}} \times \mathrm{A}\right)
$$

Where " $\mathrm{R}_{\mathrm{b}}$ " is the bulk resistance, " $\mathrm{t}$ " is the thickness of the solid polymer electrolyte and " $\mathrm{A}$ " is the area of cross-section the electrolyte. The conductivity spectra of nanocomposite polymer electrolytes for different wt\% compositions shows only spikes; this reveals that the free flow of ions takes place predominantly at the bulk resistance due to the good contacts at electrode-electrolyte interfaces hence the polarization takes place rapidly. This theory is explained on the basis of the relaxation process. ${ }^{60,61}$ From figure for the wt\% composition of PVP/PVA:GO (0.30:0.3); the ionic conductivity is found to be high $4.13 \times 10^{-4}$ at room temperature and calculated conductivity values for different wt $\%$ compositions are shown in Table-1.

Table-1: AC conductivity values of PVP/PVA: GO nanocomposite polymer films

\begin{tabular}{c|c}
\hline Nanocomposite polymer films & Conductivity values of $300 \mathrm{~K}\left(\mathrm{Scm}^{-1}\right)$ \\
\hline PVP/PVA: GO $(0.20: 0.1)$ & $3.12 \times 10^{-6}$ \\
\hline PVP/PVA: GO $(0.25: 0.2)$ & $2.09 \times 10^{-5}$ \\
\hline PVP/PVA: GO $(0.30: 0.3)$ & $4.13 \times 10^{-4}$ \\
\hline
\end{tabular}

\section{Activation Energy}

The activation energy $\left(\mathrm{E}_{\mathrm{a}}\right)$ versus GO wt\% ratio is shown in Fig. -5 . The activation energy for PVA/PVP: $\mathrm{GO}$ is due to the dominant presence of amorphous nature that facilitates the fast movement of GO motion 
RASĀYAN J. Chem.

Vol. 10 | No. 4 |1159-1166 | October - December | 2017

in polymer network. ${ }^{62}$ It is also observed that PVA/PVP: GO (0.3:0.3) film has the highest conductivity and lowest activation energy which is found to be $0.50 \mathrm{eV}$. The increase in electrical conductivity is due to these charge transfer complexes takes place in the host lattice, resulting in the decrease of activation energy.

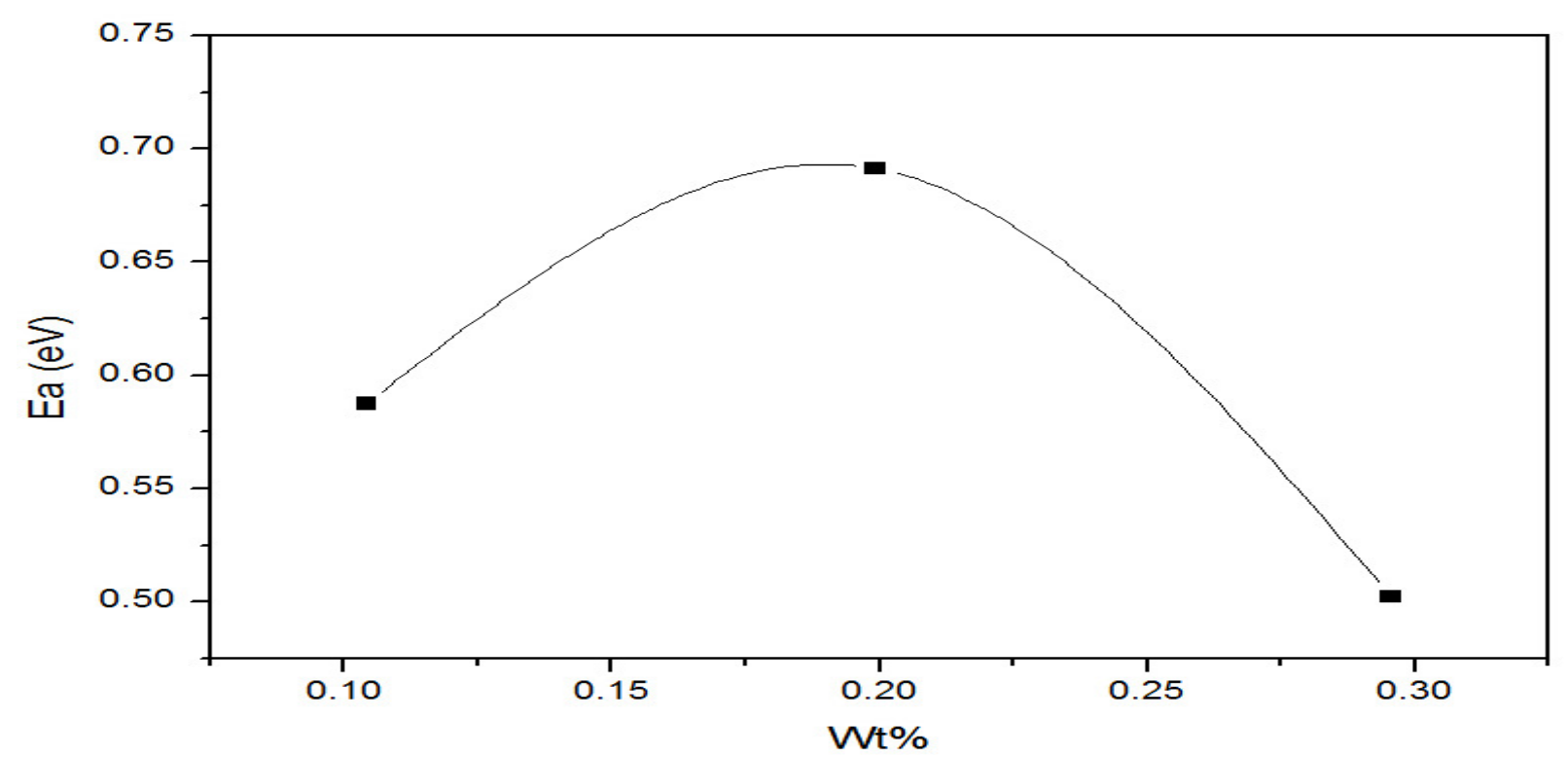

Fig.-5: Activation energies $\left(\mathrm{E}_{\mathrm{a}}\right)$ studies of PVA/PVP: GO polymer electrolyte film for (0.30:0.3) wt $\%$ ratio

\section{Dielectric Properties}

The variation of real part of the dielectric constant with the frequency for different wt $\%$ compositions of nanocomposite polymer electrolytes has shown in Fig.-6. From the figure it is concluded that as increasing the frequency, the dielectric relative permittivity is decreased predominately. The decrement is due to the formation of dielectric loss where the free movement of charge carriers takes place in the electrolyte interfaces. ${ }^{63}$

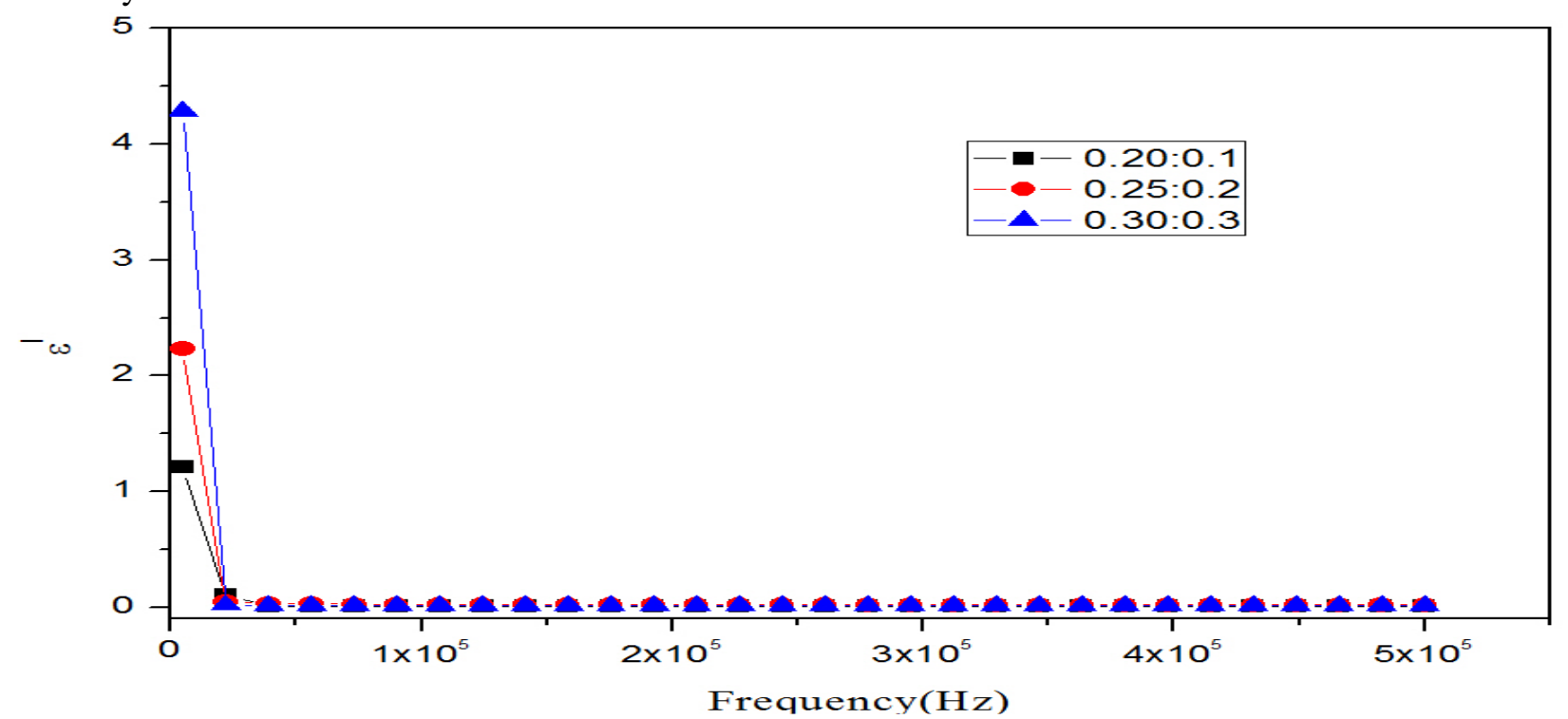

Fig.-6: Variation of the real part of dielectric constant with frequency for different wt\% ratios at $303 \mathrm{~K}$

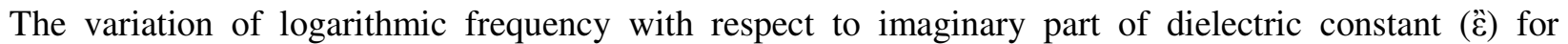
different wt\% compositions is shown in Fig. -7 . From the figure it is concluded that as increasing the 
RASĀYAN J. Chem.

Vol. 10 | No. 4 |1159-1166 | October - December | 2017

logarithmic frequency, the dielectric constant $(\grave{\varepsilon})$ is decreased gradually. The decrement of dielectric constant ( $)$ is due to the enhancement of the mobility charge carrier's takes place across the width of the space charge region and decreases with higher frequency until the energy of electron states equals to quasi-Fermi level. ${ }^{64}$

Figure- 8 shows the variation of logarithmic frequency (f) with respect to tangent loss $(\delta)$ for various wt $\%$ compositions of nanocomposite polymer electrolytes. The decrement of tangent loss is due to the increase of logarithmic frequency (f). This effect is due to the reduced proportion of amorphous material leading to a reduction in the magnitude of dispersion. The appearance of peaks suggests the presence of relaxing dipoles in the samples and also with electrical relaxation process or inability of dipoles. ${ }^{65}$

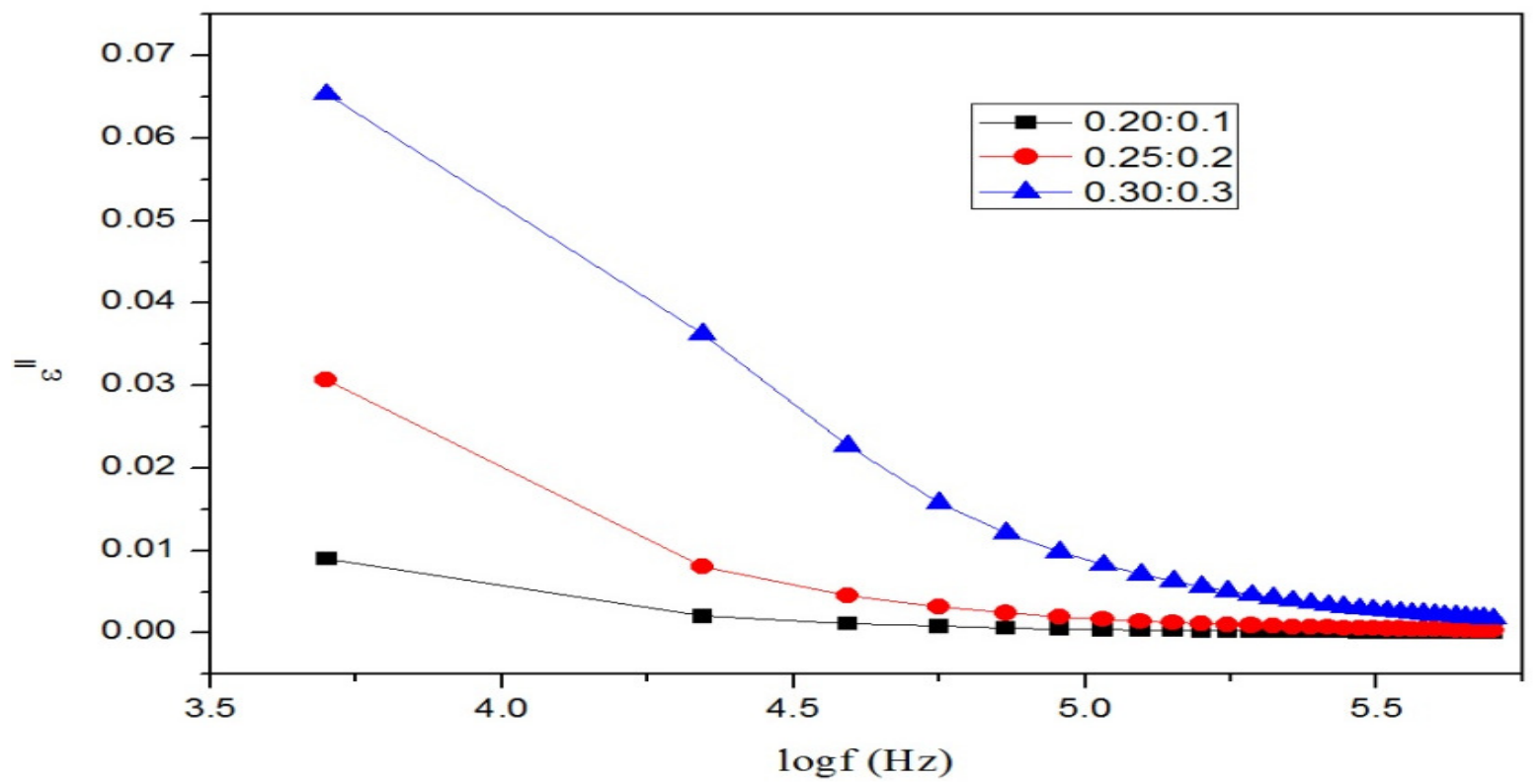

Fig.-7: Variation of $\log \mathrm{f}$ with dielectric permittivity for different wt\% ratios at $303 \mathrm{~K}$

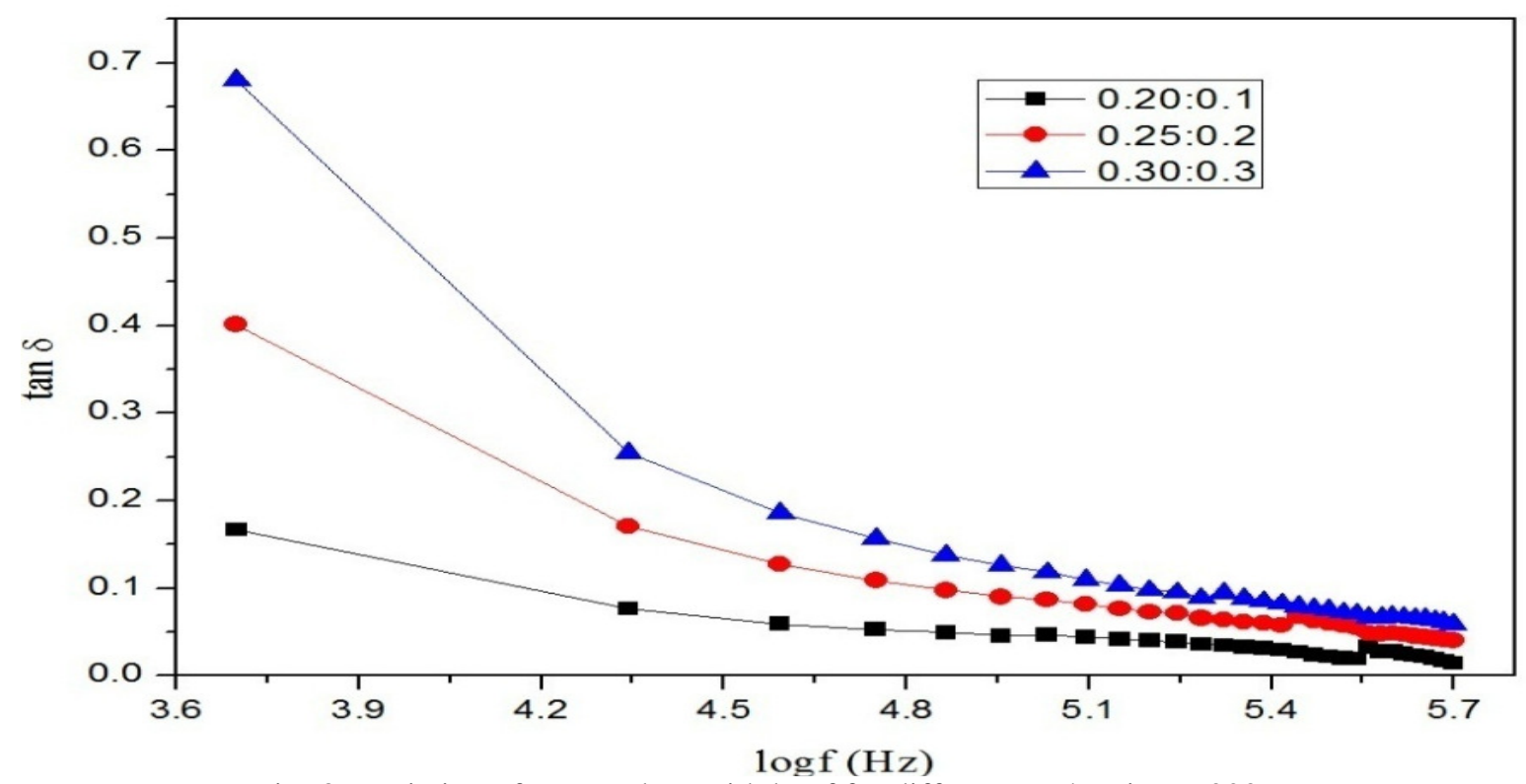

Fig.-8: Variation of tangent loss with log f for different wt $\%$ ratios at $303 \mathrm{~K}$ 


\section{CONCLUSION}

Nanocomposite polymer thin films were prepared with the combination of PVA/PVP: GO by solution cast technique. SEM revealed the smooth surface background of the polymer film which corresponds to the amorphous nature of the host polymer. DSC confirms that as increasing the GO wt $\%$, the glass transition temperature is decreased monotonically, due to lubricating effect. From the AC conductivity studies the highest conductivity for PVA/PVP: GO (0.30:0.3) was found to be $4.13 \times 10^{-4} \mathrm{Scm}^{-1}$ at room temperature. The obtained results are suitable for the fabrication of energy storage devices and in the preparation of electrochemical cells.

\section{REFERENCES}

1. A.K. Geim, K.S. Novoselov, Nature Mater., 6, 183 (2007).

2. J. Liu, Z. Yin, X. Cao, F. Zhao, L. Wang, W. Huang, H. Zhang, Adv. Mater., 25, 233 (2013).

3. K. Jug, J. Org. Chem., 48, 1344 (1983).

4. D.Y. Godovsky, Adv. Polym. Sci., 153, 163 (2000).

5. S. Guo, S. Dong, E. Wang, ACS Nano, 4, 547 (2010).

6. L. Zhang, G.J. Shi, Phys. Chem. C, 115, 17206 (2011).

7. N. Li, W. Cheng, K. Ren, F. Luo, K. Wang, Q. Fu, Chin, J. Polym. Sci., 31, 98 (2013)

8. SK. Shahenoor Basha, K.V. Kumar, M.C. Rao, J. Inorg Organomet. Polym., 27, 455 (2017).

9. J.M. Tarascon, M. Armand, Nature, 414, 359 (2001).

10. B. Kang, G. Ceder, Nature, 458, 190 (2009).

11. S.J. Richard Prabakar, Y.H. Hwang, E.G. Bae, D.K. Lee, M. Pyo, Carbon, 52, 128 (2013).

12. F.S. Saleh, E.B. Easton, J. Power Sources, 246, 392 (2014).

13. A. Saez, V. Garcia-Garcia, J. Solla-Gullon, V. Montiel, Electrochem. Acta, 91, 64 (2013).

14. R. Amin, J. Maier, Solid State Ionics, 178, 1831 (2008).

15. M.C. Rao, O.M. Hussain, J. Alloys Compd., 491, 503 (2010).

16. SK. Shahenoor Basha, K. Vijaya Kumar and M.C. Rao, Rasayan J. Chem., 9, 348 (2016).

17. M.C. Rao, Optoelect. \& Adv. Mater.(Rapid Commun.),5, 85 (2011).

18. SK. Shahenoor Basha, K. Vijaya Kumar, M.C. Rao, Rasayan J. Chem., 10, 279 (2017).

19. D.E. Fenton, J.M. Parker and P.V. Wright, Polym., 14, 589 (1973).

20. P.V. Wright, J. Polym., 7, 319 (1975).

21. K. Hyeon Kim, S. Woo Lee, Y. Chi and J.Joo Kim, Adv. Mater., 28, 2526 (2016).

22. M.C. Rao, J. Crys. Growth, 312(19), 2799 (2010).

23. M.C. Rao, K. Ramachandra Rao, Int. J. Chem.Tech Res., 6(7), 3931 (2014).

24. M.C. Rao, J. Optoelect. Adv. Mater., 13, 428 (2011).

25. SK. ShahenoorBasha, K. Vijaya Kumar, Int. J. ChemTech Res., 8, 803 (2015).

26. M.C. Rao, O.M. Hussain, Eur. Phys. J. Appl. Phys., 48(2), 20503 (2009).

27. M.C. Rao, J. Optoelect. Adv. Mater., 12, 2433 (2010).

28. M.C. Rao, O. M. Hussain, Ind. J. Eng. Mater. Sci., 16, 335 (2009).

29. P.V. Prasad, K. Ramachandra Rao, M.C. Rao, J. Mol. Struc., 1085, 115 (2015).

30. M.C. Rao, Optoelect. Adv. Mater. (Rapid Commun.), 5(5-6), 651 (2011).

31. M.C. Rao, O.M. Hussain, Optoelect. \& Adv. Mater., 13(2-4), 1109 (2011).

32. M. P. D. Parimala, M. Seshu Kumar, M.C. Rao, Rasayan J. Chem., 10(3), 825 (2017).

33. M.C. Rao, J. Optoelect. Adv. Mater., 13(1-2), 72 (2011).

34. M.C. Rao, Int. J. Chem. Sci., 10(2), 1111 (2012).

35. M.C. Rao, Optoelect. Adv. Mater. (Rapid Commu.), 6, 511 (2012).

36. M. Tejaswi, M.C. Rao, Rasayan J. Chem., 9(4), 697 (2016).

37. K. Koteswara Rao, M.C. Rao, Rasayan J. Chem., 10(3), 904 (2017).

38. M.C. Rao, J. Optoelect. \& Adv. Mater., 13, 78 (2011).

39. M.C. Rao, Sk. Muntaz Begum, Optoelect. \& Adv. Mater. (Rapid Commu.), 6, 508 (2012).

40. M.C. Rao, Optoelect. \& Adv. Mater. (Rapid Commun.), 4, 2088 (2010).

41. M.C. Rao, O. M. Hussain, Optoelect. \& Adv. Mater. (Rapid Commu.), 6, 245 (2012).

42. K. Ravindranadh, M.C. Rao, Int. J. ChemTech Res., 9(4), 598 (2016). 
43. M.C. Rao, Res. J. Rec. Sci., 2 (3), 67 (2013).

44. M.C. Rao, O.M. Hussain, Res. J. Chem. Sci., 1(7), 76 (2011).

45. M.C. Rao, J. Non-Oxide Glasses, 5, 1 (2013).

46. M.C. Rao, AIP Conf. Proc., 1728 (1), 020077 (2016).

47. G. Sunita Sundari, SK. Shahenoor Basha, M.C. Rao, Rasayan J. Chem., 10(1), 298 (2017).

48. M.C. Rao, AIP Conf. Proc., 1536 (1), 215 (2016).

49. M.C. Rao, Optoelect. \& Adv. Mater. (Rapid Commu.), 6, 245 (2012).

50. M.C. Rao, Optoelect. \& Adv. Mater. (Rapid Commun.), 10, 889 (2016).

51. T. Samuel, K. Ramachandra Rao, M.C. Rao, AIP Conf. Proc., 1728 (1), 020080 (2016)

52. M.C. Rao, Int. J. Pure Appl. Phys., 6, 365 (2010).

53. M.C. Rao, Sk. Muntaz Begum, AIP Conf. Proc., 1447, 613 (2012).

54. K. Lakshmi, SK. Shahenoor Basha,M.C. Rao, Rasayan J. Chem.,10(2), 682 (2017).

55. M.C. Rao, AIP Conf. Proc., 1447, 613 (2012).

56. M.C. Rao, AIP Conf. Proc., 1536, 27 (2013).Y. Karzazi,J. Mater. Environ. Sci., 5, 1 (2014).

57. M. Chauhan, I. Bala and Deepak Kumar, Int. J. Inno. Res. Tech., 1, 1133 (2014).

58. M.B. Armand, Solid State Ionics, 9, 745 (1983).

59. T.D. Gregory, R.J. Hoffmann and R.C. Winterton, J. Electrochem. Soc., 137, 775 (1990).

60. E.M. Abdelrazeka, H.M. Ragabb, M. Abdelaziz, Polym. Tech., 2, 1 (2013).

61. C.W. Liew, S. Ramesh, J. Mater. Res., 27, 2996 (2012).

62. S. Rajendran, R. Sankar Babu, P. Siva Kumar, J. Membr. Sci., 315, 67 (2008).

63. D. Ravinder, A.V. Ramana Reddy, G. Ranga Mohan, Mater. Lett., 52, 259 (2002).

64. A. Chandra, R.C. Agrawal and Y.K. Mahipal, J. Phys. D: Appl. Phys., 42, 1 (2009).

65. N. Shukla, K. Awalendra, T. David and Marx, Int. J. Electrochem. Sci., 9, 7644 (2014).

[RJC-1756/2017] 